\title{
Post Obstructive Pulmonary Edema Following Accidental Strangulation
}

Sir,

Post obstructive pulmonary edema is a form of noncardiogenic pulmonary edema, that appears shortly after the relief of severe upper airway obstruction. ${ }^{1}$ We report a case of post obstructive pulmonary edema in a $12 \mathrm{yr}$ boy following accidental near strangulation.

A 12-yr-old boy was brought to pediatrics emergency with alleged history of strangulation while playing on a swing. The child took several turns in the swing to one side and then suddenly turned towards the other side when he fell down while his neck got entangled in the loop of rope. He remained strangulated for about $10 \mathrm{~min}$, before he was rescued by his parents and brought to the hospital. On admission the child was irritable; pulse rate was 140 per minute, all peripheral pulses well palpable, blood pressure $100 / 60 \mathrm{mmHg}$. His respiratory rate was $40 / \mathrm{min}$, with no evidence of respiratory distress. There was a diffuse ligature mark over his neck and conjunctiva was suffused. Pupils were semi dilated, with normal reaction to light; B/L fundii were normal. Twelve hours after admission, the patient developed tachypnea, associated with frothy secretions from mouth. Examination of respiratory system revealed B/L crepitations. Arterial blood gas analysis showed hypoxemia $\left(\mathrm{PaO}_{2} 49 \mathrm{mmHg} ; \mathrm{SpO}_{2} 82 \%\right)$. The child was ventilated on following settings: mode SIMV, ventilatory rate 20/min, PIP $16 \mathrm{cmH}_{2} \mathrm{O}, \mathrm{PEEP} 3 \mathrm{cmH}_{2} \mathrm{O}$ and $\mathrm{FiO}_{2} 50 \%$. Intravenous furosemide was given. Chest Radiograph collected later showed diffuse bilateral non- homogenous opacities. After starting mechanical ventilation saturation improved to $99 \%$, blood gas revealed respiratory alkalosis with hyperoxia (7.444/30.6/140.8/20.4/-1.8/99.2\%). Echocardiography and CPK-MB $(4.2 \mu \mathrm{g} / \mathrm{L})$ turned out to be normal. By next 24 hrs, Chest Radiograph was normal and the child was successfully extubated.

Type I post obstructive pulmonary edema follows a sudden severe episode of upper airway obstruction, as happened in our patient and type II develops after surgical relief of chronic upper airway obstruction, as has been reported after tonsillectomy. ${ }^{2}$

Post obstructive pulmonary edema usually develops within $60 \mathrm{~min}$ of relief from acute upper airway obstruction, although in some cases it has been reported to be delayed up to $6 \mathrm{hrs} .{ }^{3}$ However, in the present patient the onset was delayed beyond 12 hrs after the precipitating event. Hence, all patients with strangulation injury should be closely monitored for the development of pulmonary edema so that early treatment may be instituted. Management with supplemental oxygen and CPAP or PEEP and diuretics promotes rapid clearance of pulmonary edema. ${ }^{4}$

To conclude, post obstructive pulmonary edema is a known complication following strangulation injury, hence should be anticipated and managed accordingly. Prognosis in these cases is good and most patients respond rapidly to treatment, as happened in the present patient.

\section{Abhijeet Saha, Anuradha Bansal and Saranjit Kaur \\ Department of Pediatrics, Government Medical College $\mathcal{E}$ Hospital, Sector 32 B, Chandigarh, India. E-mail:drabhijeetsaha@yahoo.com}

[DOI-10.1007/s12098-010-0016-2]

\section{REFERENCES}

1. Aggarwal R, Anant S, Vardhan H. Pulmonary edema in a survivor of suicidal hanging. MJAFI 2004; 60: 188-189.

2. Guffin TN, Har-el G, Sauder A, Lucente FE, Nash M. Acute post obstructive pulmonary edema. Otolaryngol Head Neck Surg 1995; 112: 235-237.

3. Sofer S, Bar- Ziv J, Scharf SM. Pulmonary edema following relief of upper airway obstruction. Chest 1984; 86: 401-403.

4. Scherer R, Dreyer P, Jorch G. Pulmonary edema due to partial upper airway obstruction in a child. Intensive Care Med 1988; 14: 661-662. 